\title{
Dr. Maurice Choux's Presidential Address 10th Annual Meeting of the International Society for
}

\section{Pediatric Neurosurgeons}

\section{Philadelphia, Pa., September 12-15, 1982}

Dear Colleagues,

Is a scientific society to be considered as a well-established institution after 10 years of existence?

I will try to evaluate with you whether we have been a successful association or only a group of friends, meeting every year in selected nice places.

My purpose is to determine whether our goals fixed in 1972 have been reached. In other words: is pediatric neurosurgery, in 1982, a recognized speciality with its dignity, status and ethics?

When we founded the society, our main purpose was not only to meet persons interested in pediatric neurosurgery but also to change opinions, and to affirm the existence of an authentic, true and complete branch of neurosurgery. When we remember how pediatric neurosurgery was considered 10 years ago, we can appreciate the significant progress that has been accomplished, even though the battle is not finished yet. For many years, pediatric neurosurgery was left to a surgeon, usually the youngest resident of the neurosurgical department, who took care of complicated shunts, huge malformations and other catastrophic cases. But arteriovenous malformations or posterior fossa tumors in children were dealt with by general neurosurgeons. Officially, in maintaining this principle, many neurosurgeons wanted to preserve the unity of neurosurgery. Progressively and quietly our Society has demonstrated that, if a general neurosurgeon is able to operate on an infant, a general neurosurgical departe-ment is not always able to manage this small patient.

I am convinced that an infant with hydrocephalus, a tumor, or a malformation will be managed more successfully in a pediatric department, a pediatric operating theater, a pediatric intensive care unit, by a pediatric anesthesiologist or a pediatric neuroradiologist, that is in a pediatric environment. For many years, I have tried to demonstrate that when creating a pediatric neurosurgical department it is easier to find a pediatric neurosurgeon than to create such an environment.

A few examples will illustrate what I mean. Intracranial tumors in neonates and infants have long been considered as having a very poor surgical prognosis, with an operative mortality of 50-60\%. Actually, in pediatric neurosurgical series the operative mortality is around $15-20 \%$. The management of an infant with a craniopharyngioma or a third-ventricular tumor, for example, will be completely different in a pediatric neurosurgical unit than in a general neurosurgical department. The removal will be technically good but preoperative (C) 1983 S. Karger AG, Basel O3O2-28O3/83/OlO4-O286 \$ 2.75/0 
investigations, the anesthetic period, intensive care and follow-up will not be as adequate or even insufficient.

Another example is hydrocephalus and its treatment by shunt. In general series, the proportion of shunt complications, mechanical or infectious, can be quite high, sometimes around $30-45 \%$. A pediatric neurosurgeon will consider that a shunt is one of the most risky operations in neurosurgery. He will know every problem which can appear at each step of the operation, because of his experience with hydrocephalic patients, complications, material and because he has inserted many shunts every year.

The third example is spina bifida. Still today, in many places, closure of spina bifida and even shunting are done by pediatric surgeons. Why? Because for a long time neurosurgeons were not interested in a lesion which they automatically considered fatal or functionally catastrophic. We know that the closure of a myelomeningocele is not a simple problem, and it will not be restricted to lopping of the malformation. Recent meetings have fully demonstrated that only pediatric neurosurgeons have the ability to manage neurologically this complex malformation, from the start, that is the closure, to the end, that is the shunting and the Arnold-Chiari malformation. In these meetings on spina bifida, I have always declined to talk about shunting or Arnold-Chiari malformations only if the initial management and the closure of the malformation were not talked about by a neurosurgeon.

When a resident wanted to dedicate himself to pediatric neurosurgery he would always find someone who amicably discouraged him, explaining the consequences of his decision: he would be a sort of pariah, aside from the great neurosurgical field, doing shunts and shunts, disconnecting shunts and closing spina bifida. In fact, we know very well that in an independent pediatric neurosurgical department we are confronted with all kinds of different neurosurgical lesions.

One interesting point to know is the percentages of what we call typical pediatric neurosurgical procedures (i.e., shunts, surgery for myelomeningoceles or craniosynostosis) in comparison with other procedures. I have calculated them in four pediatric neurosurgical departments: those oîK. Till in London; of T. Raímondi in Chicago; of the Hospital for Sick Children (HSC) in Toronto and my own department in Marseilles. I found the following figures: Till 48\%; Raimondi $63 \%$; HSC $60 \%$; Choux 52\%. This means that in $40-50 \%$ of the cases we have to treat lesions other than shunts, spina bifida or craniosynostosis. In pediatric neurosurgery, of course, we are not familiar with acoustic neurinomas or aneurysms, but we can survive without the experience of these lesions. Besides, most general neurosurgeons in the world have no experience either with this lesions.

We are now strong enough to convince the last detractors. We have a recognized International Society. We have each year more and more pediatric neurosurgical departments, meetings, courses. But many problems remain as, for example, the implantation of pediatric neurosurgical departments in towns without children's hospitals, the association with a pediatric neuroradiologist, with a pediatrician, the use of a pediatric intensive care unit, the relationship with a general neurosurgical department in small places.

The problems are more acute in the third world, in countries where neurosurgeons are rare, and where neurosurgery is considered as a luxury. Pediatric neurosurgery would interest many neurosurgeons in these countries since in many of them, children represent the majority of the population. I think that the International Society for Pediatric Neurosurgery must take an interest in neurosurgery in third-world countries and in their specific problems.

We cannot ignore that the majority of hydrocephalic children in the world are not treated because of financial reasons; that the majority of children with medulloblastomas are

Varia 
not irradiated and that the majority of children with craniosynostosis in the world are not operated on and a great proportion become blind - 50\% of the blind people in some African countries are blind due to nontreated craniosynostosis.

Many countries need a cheaper valve to treat hydrocephalic children: the more sophisticated, and consequently the more expensive a valve will be, the less will its implantation be generalized.

The International Society must watch these problems. It must become an increasingly international organization, meeting in every place around the world, regardless of accommodation, social or political considerations. It must pay special attention to under-developed countries, helping their members, facilitating the attendance to the meetings for them.

In this way, it will continue to be the official representative of pediatric neurosurgery, officially admitted to the World Federation meetings and soon becoming an official member of the World Federation Committee.

I take the opportunity to thank my friend, Luis Shut, one of the most active pediatric neurosurgeons I have known, for his activity as Secretary of the Society and for organizing the 10th meeting of our Society.

I am happy to have been your President for 1 year and to give over the Presidency to my friend Satoshi. Every one has appreciated his intelligence, his political sense and his enthusiasm for developing pediatric neurosurgery in Japan. Under his direction the future of the Society is assured.

Announcement

Name of course: The Pediatric Spine

Course organizer: A.J. Raimondi, MD

Date: October 25-27, 1983

Sponsor: $\quad$ Northwestern University Medical School

CME credits: 21 Category I Credits

Location: Alumni Center for Continuing Education, Northwestern Univer-

sity Medical School, 301 E. Chicago Avenue, Chicago, IL 60611 USA

Telephone: (312)649-8533 